\title{
Formação pedagógica de professores de nutrição: uma omissão consentida?
}

\author{
Teacher training for nutrition professors: \\ a tacitly accepted omission?
}

Nilce Maria da Silva Campos COSTA $^{1}$

RES U M O

Apesar dos novos papéis preconizados pelas Diretrizes Curriculares Nacionais aos profissionais de Nutrição, pouca atenção tem sido dada ao desenvolvimento docente para atuação nos novos cenários. O objetivo deste ensaio é o de discutir um dos desafios à formação do nutricionista, a prática docente e a formação pedagógica do professor da área da saúde, para pensar formas de oportunizar um ensino de melhor qualidade, com base em autores que discutem a docência universitária. Identificam-se como causas da resistência docente às mudanças, a desvalorização das atividades de ensino e a supremacia das atividades de pesquisa nas universidades. O estudo permitiu sugerir a necessidade de reflexão por parte dos professores de Nutrição sobre as questões da docência universitária e sobre o desenvolvimento docente em uma perspectiva crítica e reflexiva, que possa ancorar mudanças pedagógicas necessárias à formação de nutricionistas.

Termos de indexação: Ciências da nutrição. Docentes. Educação. Saúde.

\section{A B S T R A C T}

Despite the new roles called in for the National Curricular Guidelines for teachers in nutrition courses, little attention has been paid to the professional development of the nutrition professional acting as a teacher. Based on the work of authors who discuss university teaching, this essay discusses some of the challenges involved in training nutritionists, such as teaching practice and teacher training for the professor in the health field, with the goal of providing higher-quality teaching. The devaluation of teaching and the supremacy of research at universities have been identified as the causes of teachers' resistance to change. This study reveals the need for professors of nutrition to reflect on the questions of university teaching and teacher development from a critical and reflective perspective which can anchor the pedagogical changes needed to train the nutritionist.

Indexing terms: Nutritional science. Faculty. Education. Health.

\footnotetext{
$\overline{1}$ Universidade Federal de Goiás, Faculdade de Nutrição. R. 227, Qd. 68, s/n., Setor Leste Universitário, Campus I, 74605-080, Goiânia, GO, Brasil. E-mail: <nilce@fanut.ufg.br>.
} 
I N T R O D U Ç Ã O

A realidade desenhada pela contemporaneidade na ciência, na política e no trabalho revela demandas inusitadas para aqueles que desejam ser profissionais de saúde. As transformações ocorridas no Brasil e no mundo nas últimas décadas, a evolução da ciência e da tecnologia e a crise paradigmática em diversas áreas do conhecimento humano têm gerado um novo modelo de sociedade em que a formação universitária coloca-se não apenas como condição para a atuação no mercado de trabalho, mas também como direito do indivíduo para a construção da cidadania'.

O ensino superior em saúde, de modo geral, tem sido, nas últimas décadas, alvo de críticas. Em vários países tem crescido o questionamento, por parte da sociedade, sobre a capacidade de as instituições de ensino superior cumprirem as finalidades gerais de seus programas, que deveriam ser as de desenvolver o potencial intelectual dos estudantes, incentivar a capacidade de análise, julgamento e avaliação crítica e construir a habilidade para resolver problemas e mobilizar o raciocínio crítico, além de estabelecer uma abordagem criativa e inquiridora ${ }^{2}$.

As modificações no mundo do trabalho têm exigido do nutricionista novos atributos profissionais. De um lado, criatividade, autonomia na busca do conhecimento e capacidade de liderança; de outro, competência para desenvolver quadros teórico-analíticos e críticos que Ihes permitam acompanhar não só o desenvolvimento do conhecimento e da formação profissional, como também a capacidade de se comunicar internacionalmente, desenvolver a crítica ao novo, além de desempenhar a profissão de forma contextualizada e em equipe multiprofissional Tais atributos são incompatíveis com a aprendizagem fragmentada, pautada na concepção de que a formação significa apenas alcançar objetivos previamente estabelecidos, que definem a conduta esperada, as condições em que serão alcançados e o padrão aceitável de desempenho dos alunos.
A formação de profissionais voltada apenas para o desempenho técnico específico da sua área de atuação, não pode mais ser aceita pelas instituições de ensino superior, cuja preocupação deve voltar-se para a formação do profissional cidadão, competente técnica e cientificamente, mas sobretudo com uma ampla visão da realidade em que vai atuar e com elementos para transformá-la³.

Enfatiza-se cada vez mais a necessidade de um profissional de saúde apto a atuar e contribuir com a sociedade em um contexto de profundas mudanças, não somente em seu próprio campo profissional, mas também nos campos político e social ${ }^{4}$.

A integralidade pode ser tomada como eixo para apoiar as mudanças na formação de profissionais de saúde e implicar uma compreensão ampliada da saúde, na articulação de saberes e práticas multiprofissionais e interdisciplinares e na inovação das práticas de atenção à saúde 5 .

A homologação das Diretrizes Curriculares Nacionais ${ }^{6}$ (DCN), em 2001, contribuiu para impulsionar mudanças no ensino em saúde, incluindo-se um perfilamento do ensino de Nutrição, aliado à noção de equipe de saúde, demonstrando a preocupação com a consolidação, em leis e decretos, das mudanças necessárias nas ações e na formação de trabalhadores para o setor. A proposta de formação dos profissionais de saúde apresentada pelas DCN pode ser considerada um avanço no contexto das necessidades de saúde da população brasileira, pois enfatiza a formação de atitudes voltadas para a saúde, a cidadania e a atuação em equipe, avançando também na integração entre ensino e serviço, vinculando a formação acadêmica às necessidades sociais da saúde. Busca-se um preparo adequado para uma assistência de qualidade em saúde, com abordagem integral, interdisciplinar, multiprofissional e eqüitativa.

As DCN trazem, também, novos papéis e contextualizam novos cenários de ensino nos quais devem se inserir os docentes universitários. O artigo 9 das DCN esclarece que o projeto pedagógico 
dos cursos de Nutrição deverá ter no aluno o centro da aprendizagem e no professor um facilitador e mediador do processo ensino-aprendizagem ${ }^{6}$. Assim, o professor deve estar atento ao seu exercício profissional e às transformações da contemporaneidade, tendo também o dever de levar os alunos a discutir os aspectos políticos da profissão e de seu exercício na sociedade, para que nela possam se posicionar como cidadãos e profissionais.

Apesar das recomendações das DCN, de que o professor deve dominar mais do que o conhecimento técnico disciplinar, estarão os docentes dos cursos de Nutrição conscientes da abrangência das competências advindas dos novos papéis a serem desempenhados?

Reconhece-se a necessidade de mudanças na prática docente em saúde e discute-se a necessidade de formação do professor reflexivo em cursos da área com mais longa tradição de debates sobre ensino, como a enfermagem, a medicina e a odontologia ${ }^{4,7-9}$. Em relação aos cursos de Nutrição, praticamente convive-se com a inexistência de publicações na literatura brasileira e com a falta de discussões sobre esta temática.

O objetivo deste artigo é o de discutir um dos desafios à formação do nutricionista, a prática docente e a formação pedagógica do professor da área da saúde, para pensar formas de oportunizar um ensino de melhor qualidade. Busca-se contribuir para a reflexão dos professores e para a elaboração de propostas de formação docente que ancorem mudanças pedagógicas no ensino de nutrição, sob uma perspectiva crítica e reflexiva.

\section{PRÁTICA DOCENTE EM SAÚDE}

Mesmo nos cursos de medicina, em que historicamente se discute a formação docente via Associação Brasileira de Educação Médica (ABEM) e por meio de publicações específicas para a discussão desta temática, como a Revista Brasileira de Educação Médica, enfrenta-se o reconheci- mento da necessidade de mudanças no ensino e dificuldades para que estas se consumam.

Os próprios professores mostram-se resistentes às modificações, continuam a ensinar como sabem, evitam às novas metodologias de ensino-aprendizagem ${ }^{10}$ e incorporar concepções pedagógicas mais avançadas ou de vanguarda, especialmente quando envolvem relações democráticas entre professores e alunos ${ }^{11,12}$. Em outras palavras, há uma tendência a encarar com ceticismo ou descaso os aspectos pedagógicos da docência universitária.

Um primeiro fator a ser considerado quando se discute a resistência dos professores em aceitar mudanças em sua prática docente é o desmerecimento da atividade de ensino nas universidades em geral e nas públicas, em particular, de maneira crescente, devido à condição da pesquisa no âmbito da pós-graduação e ao pouco desenvolvimento de tecnologias assistenciais. Nos cursos de medicina, por exemplo, alguns autores destacam que a docência é considerada uma atividade secundária à profissão médica e o trabalho docente não é assumido como profissão ${ }^{13}$. O critério de contratação dos docentes nesses cursos centra-se na qualidade de seu desempenho na área técnica de atuação, fato constatado também em outros países ${ }^{14,15}$.

Soma-se a isto a constatação de uma característica do ensino superior, que é a da ciência desprofissionalizada (sem formação pedagógica). Praticamente não existe preparo pedagógico para os professores universitários, fato que, sem dúvida, contribui para a deficiência no domínio da área educacional $\left.\right|^{4,5,16-23}$.

A desvalorização das atividades de ensino prejudica a qualidade do ensino ministrado, pois a ação docente, além do vínculo com o domínio do conteúdo disciplinar, deve estar vinculada também à gestão do processo educativo e à preparação dos alunos para aprender a aprender.

Um segundo fator a ser levado em conta na resistência docente às mudanças é o fato de que os estímulos para a atuação e os critérios de 
progressão na carreira têm se fundamentado mais na produção científica que no exercício da docência. Contribui para esse fato o próprio desenvolvimento do conhecimento científico específico de cada profissão, que tem se tornado cada vez mais especializado, fragmentado e "incapaz de regular ou orientar a prática docente e de descrever ou explicar a riqueza e a complexidade dos fenômenos educativos ${ }^{24 "}$.

Apesar de as instituições de ensino superior serem basicamente instituições formativas e, assim, terem na formação oferecida aos alunos a variável de maior importância, o ranking é feito com base em indicadores de produção científica ou técnica. O potencial formativo fica secundarizado. Muitas vezes, "os professores vêem a si mesmos mais como pesquisadores (no campo científico) ou como profissionais (no campo aplicado) do que como professores, de fato 21 " (p.114). A supremacia das atividades de pesquisa é um fator que tem levado os professores a se afastarem das atividades docentes. Pesquisar e ensinar "não são atividades incompatíveis, mas competem no tempo disponível do docente/pesquisador ${ }^{4 "}$ (p.154).

\section{F O R M A ÇÃ O PE D A G Ó G I C A DO PROFESSOR DA ÁREA DA SAÚ DE}

No Brasil, a legislação aborda a formação do docente de ensino superior de forma superficial. A Lei de Diretrizes e Bases da Educação Nacional ${ }^{25}$ trata, em seu artigo 66, sobre o tema: "a preparação para o exercício do magistério superior far-se-á em nível de pós-graduação, prioritariamente em programas de mestrado e doutorado".

Estudos sobre a docência na área médica revelam que a atuação do professor restringe-se à reprodução dos modelos considerados válidos, apreendidos anteriormente, e à sua experiência prática cotidiana ${ }^{17,26}$. Os professores têm idéias, atitudes e comportamentos sobre o ensino, provenientes da formação recebida durante o período em que foram alunos. A atuação docente, nesses casos, guarda uma dimensão inconsciente e não inteiramente racional. Têm papel mais ou menos importante a experiência própria como aluno, o modelo de ensino predominante no sistema universitário e as reações dos alunos. Essa prática enquadra-se no que Mizukamii ${ }^{27}$ denomina de teoria prática de ensino, na qual os professores agem "na base de várias teorias da prática e, quer estejam ou não conscientes de tais teorias, seu trabalho é racional, pelo fato de ser intencional" (p.43).

A influência desta formação incidental é considerável, posto que os docentes a adquirem de forma não-reflexiva, como algo natural que escapa a críticas e transforma-se em um conceito espontâneo sobre o que seja ensinar ${ }^{28,29}$. A formação é proporcionada pela experiência prática cotidiana. Venturelli ${ }^{22}$ considera desfavorável este tipo de formação, pois a improvisação educacional "es la mejor forma de eternizar las limitaciones de un método que el tiempo ha sobrepasado" (p.23).

Para Benedito ${ }^{30}$ aprende-se a ser professor universitário "mediante um processo de socialização em parte intuitiva, autodidata ou" ... seguindo a rotina dos outros". Benedito assinala que, embora não se deva desconsiderar a capacidade autodidata do professorado, a formação proporcionada pela experiência é insuficiente.

Para Sacristan ${ }^{31}$ (p.183), o professor passa "da experiência passiva como aluno ao comportamento ativo como professor, sem que Ihe seja colocado, em muitos casos, o significado educativo, social e epistemológico do conhecimento que transmite ou faz seus alunos aprenderem. Passa de aluno receptor a consumidor acrítico de materiais didáticos e a transmissor com seus alunos".

Apenas recentemente os professores universitários estão se tornando conscientes de que a atividade docente, como a pesquisa e a prática de qualquer profissão, exige capacitação própria e específica. Na atividade docente, além das competências específicas para o exercício de uma profissão, existem as competências próprias do docente universitário, seja em determinada área 
do conhecimento, seja no domínio na área pedagógica, seja no exercício da dimensão política da docência universitária ${ }^{32-34}$.

Zabalza ${ }^{21}$ destaca as três dimensões do papel do docente no ensino superior: 1) a profissional, que permite o acesso a componentes que definem a profissão: a construção da identidade profissional, os dilemas do exercício profissional, as necessidades de formação inicial e permanente; 2 ) a pessoal: o tipo de envolvimento e de compromisso pessoal, os ciclos de vida dos docentes, as situações pessoais que afetam o exercício profissional, as fontes de satisfação e insatisfação no trabalho e 3) a administrativa: os aspectos relacionados às condições contratuais, aos sistemas de seleção e promoção, aos incentivos e às obrigações do exercício profissional.

Garcia $^{35}$ (p.32), que discute vários conceitos/paradigmas sobre formação de professores, considera que existe um "escasso desenvolvimento teórico e conceptual da formação permanente ou desenvolvimento profissional dos docentes".

Estudiosos de vários países têm manifestado preocupação com a necessária mudança no trabalho docente. $O$ ensino tradicional vem paulatinamente dando lugar a práticas alternativas que se propõem a levar ao desenvolvimento global dos educandos ${ }^{36,37}$.

Sacristan ${ }^{31}$ considera que o processo de renovação pedagógica, que preconiza o papel central para os professores no planejamento de sua prática, deve partir da análise das condições objetivas do trabalho profissional dos docentes, "para propiciar saídas realmente libertadoras, ao mesmo tempo em que se é consciente das dificuldades objetivas do plano" (p.109).

O modelo tradicional de formação pedagógica do docente universitário está em crise e precisa ser repensado, pois mostra "uma tendência de formação para o mercado, dentre as lógicas neoliberais. O docente leciona nos moldes da tradição, dentro das certezas do passado ${ }^{37 " ~(p .87) . ~}$

Schmidt et al. ${ }^{36}$ ao discutirem o conceito de prática pedagógica, apresentam duas ver- tentes: a prática pedagógica repetitiva e a prática pedagógica reflexiva. Na primeira, as ações parecem acontecer "sem dúvidas e reflexões", podendo levar o professor à alienação do seu processo de trabalho: é o caráter mecânico e burocratizado da prática. Já a prática reflexiva tem como preocupação a produção de mudanças qualitativas no processo de ensino e, para isso, procura instrumentalizar-se com um conhecimento crítico e aprofundado da realidade.

Concepções diferenciadas de prática docente têm sido assinaladas por vários autores, como Cunha ${ }^{18}$, que considera a existência de duas concepções de ensino: "uma bem delineada", de perspectiva reprodutiva, na qual "prepondera a reprodução do conhecimento cientificamente acumulado". Outra, "ainda emergente", que concebe o conhecimento como um processo "no qual a dúvida e a incerteza são estímulos à produção do aprendiz" (p.389).

A crítica generalizada ao tradicionalismo e à racionalidade técnica tem conduzido à emergência de propostas alternativas sobre o papel do professor, com a visão da formaçãa em uma perspectiva mais ampla e mais humana, como o proposto por Schön, o da "prática reflexiva" 38,39.

Schön ${ }^{39,40}$ sugere o incremento das práticas reflexivas já emergentes e o estímulo à sua introdução na formação inicial e continuada do professor, para que possam aprender a partir da análise e da interpretação de sua própria atividade. Esse autor considera que existem "zonas incertas", não previsíveis na prática profissional, para as quais os docentes não se encontram preparados para capacitar os alunos a uma atuação competente. Propõe, então, "o repensar da educação para a prática reflexiva". O professor reflexivo é aquele que pensa-na-ação, interrogando-se sobre as alternativas possíveis para um determinado momento e avaliando seus resultados.

Schön ${ }^{40}$ acrescenta que as escolas devem repensar tanto a "epistemologia da prática quanto os pressupostos pedagógicos sobre os quais seus currículos estão baseados e devem adaptar suas instituições para acomodar o ensino prático 
reflexivo" (p.25). O próprio autor adverte, entretanto, que o ensino prático reflexivo corre o risco de se tornar uma ilha isolada tanto do mundo da prática quanto do ensino tradicional. Propõe, para evitar tal isolamento, o desenvolvimento de atividades "que conectem a reflexão-na-ação dos profissionais competentes com as teorias e técnicas ensinadas como conhecimento profissional nas disciplinas acadêmicas" (p.227).

Entre os obstáculos à implantação da prática reflexiva encontram-se a epistemologia dominante na universidade e o currículo prescritivo. Nóvoa ${ }^{41}$ defende a necessidade de uma formação que estimule uma perspectiva crítico-reflexiva e que forneça ao professor meios de desenvolver um pensamento autônomo e permita compreender a globalidade do sujeito, assumindo a formação como um processo interativo e dinâmico. As práticas de formação que tomam como referência as dimensões coletivas contribuem para a emancipação profissional e para a consolidação do professor como um profissional autônomo na produção dos seus saberes e dos seus valores.

É importante considerar, entretanto que, via de regra, os docentes não estão preparados para a prática reflexiva e necessitam de orientação, estímulo e cooperação. As tentativas de mudança geram uma sensação de insegurança, o chamado mal-estar docente, visto que já se encontram adaptados "a um trabalho bem definido - o ensino, a transmissão de conhecimentos" $^{\prime \prime 2}$ (p.11).

O caminho aberto pela necessidade da reflexão como modelo de formação propôs uma série de intervenções que tornou possível, nos planos teórico e prático, um novo modo de formar professores. Apesar das críticas feitas à proposta de Schön, é inegável a sua contribuição para uma nova visão da formação. O ponto principal da crítica a Schön é que o conhecimento pode e vem da prática, mas não há como situá-lo exclusivamente nela. Esta crítica deve ser dirigida à racionalidade técnica, que defende a idéia de que os profissionais solucionem problemas a partir da seleção dos meios técnicos. O questionamento a este tipo de profissionalização é que, quando se esgotam o repertório teórico e os instrumentos construídos como referenciais, o professor não sabe como lidar com a situação.

Assim, encontrar estratégias práticas adequadas ao fazer docente constitui uma tarefa essencial para a formação do educador ${ }^{42,43}$. Ainda que não seja o único elemento do processo, não há como desconhecer que o professor é o agente principal das decisões. Mesmo desconhecendo o arbítrio que envolve suas escolhas, é o professor que concretiza a definição pedagógica e, na estrutura acadêmica de poder, representa a maior força ${ }^{44}$.

\section{CONSIDERAÇÕES FINAIS}

O corpo docente é um dos elementos centrais para o êxito das reformulações necessárias à formação do nutricionista e o alicerce fundamental sobre o qual devem ser instituídas as bases das mudanças introduzidas na formação, mas pouca atenção tem sido dada ao desenvolvimento profissional dos docentes dos cursos de Nutrição.

Assim, um dos desafios da formação de nutricionistas é a formação pedagógica dos professores, que precisam ter uma visão global da profissão docente. Para isso, deve-se enfrentar o problema do desenvolvimento de programas de formação docente de forma constante, pois se faz necessária uma nova dinâmica de atuação docente atuante perante as complexidades do mundo atual, e também que possa propiciar aos alunos as ferramentas intelectuais essenciais para uma atuação profissional competente.

É imprescindível, portanto, discutir o ensino de Nutrição e a formação do nutricionista incluindo questões como a formação docente e as práticas educativas empreendidas. Porém, este debate não pode se dar de forma isolada em cada curso de Nutrição, mas em instâncias representativas da categoria profissional, que devem oportunizar esta discussão, visto que nenhuma transformação acontece de forma isolada. Os fatos, as escolhas e as decisões são historicamente construídas. 
Não bastará a elaboração de projetos político-pedagógicos inovadores, se os docentes não estiverem preparados para desenvolvê-los. Se as instituições de ensino de Nutrição reconhecerem o fato de que o professor não foi formado para ensinar, talvez possam contribuir para mudar essa situação, pondo o desenvolvimento docente como caminho da educação em nutrição, na direção propicia à construção de novos patamares de desempenho profissional na área.

\section{REFERÊ N CIAS}

1. Flecha R, Tartajada I. Desafios e saídas educativas na entrada do século. In: Imbernon F, organizador. A educação no século XXI. Porto Alegre: Artmed; 2000. p.21-36.

2. Mamede S, Penaforte J, organizadores. Aprendizagem baseada em problemas: anatomia de uma nova abordagem educacional. Fortaleza: Hucitec; 2001.

3. Amorim STSP, Moreira HCTE. A formação de pediatras e nutricionistas: a dimensão humana. Rev Nutr [periódico eletrônico]. 2001 ago [acesso 2007 jan 10]; 14(2). Disponível em: <http://www. scielo.br/rn>

4. Lampert J. Tendências de mudança na formação médica no Brasil: tipologia das escolas. São Paulo: Hucitec; 2002.

5. Ceccim RB, Feuerwerker LCM. Mudanças na graduação das profissões de saúde sob o eixo da integralidade. Cad Saúde Pública [periódico eletrônico] 2004 [acesso 2007 jan 10]; 20 (5). Disponível em: <http://www.scielo.br/>. doi: 10.1590/s0102-311 X2004000500036.

6. Brasil. Ministério da Educação. Conselho Nacional de Educação. Resolução CNE/CES n5, de 07/11/2001. Diretrizes Curriculares Nacionais do Curso de Graduação em Nutrição. Brasília: Câmara de Educação Superior; 2001.

7. Faria JIL, Casagrande LDR. A educação para o século XX e a formação do professor reflexivo na enfermagem. Rev. Latino-Am Enfermagem [periódico eletrônico]. 2004, set [2007 jan 10]; 12(5). Disponível em: <http://www.scielo.br/>. doi: 10.1590/s0104-11692004000500017.

8. Secco LG, Pereira MLT. Formadores em odontologia: profissionalização docente e desafios político-estruturais. Cienc Saúde Coletiva [periódico eletrônico] 2004 [citado em 2007 jan 10]; 9(1). Disponível em: <http://www.scielo.br/rn>. doi: 10.1590/1413-81232004000100011.
9. Pereira OP, Almeida TMC. A formação médica segundo uma pedagogia da resistência. Interface-Comunic. Saúde Educ. 2005; 9(16):69-79.

10. Koifman L. A teoria de currículo e a discussão do ensino médico. Rev Bras Educ Méd. 1998; 22(2-3): 37-47.

11. Feuerwerker L. Educação médica na América Latina. In: Feuerwerker L. Mudanças na educação médica e residência médica no Brasil. São Paulo: Hucitec; 1998. p.51-95.

12. Feuerwerker L. Além do discurso de mudança na educação médica: processos e resultados. São Paulo: Hucitec; 2002.

13. Batista NA, Souza da Silva SH. A função docente em medicina e a formação/educação permanente do professor. Rev Bras Educ Med. 1998; 22(2/3): 31-6.

14. Mcleod PJ, Steinert Y, Meagher T, Mcleod A. The $A B C s$ of pedagogy for clinical teachers. Med Educ. 2003; 37:638-44.

15. Finucane P, Rolfe I. Graduates' verdict on medical teachers: the minority who teach do it well. Med Teach. 1996; 18(1):57-9.

16. Comissão Interinstitucional de Avaliação do Ensino Médico. Relatório final da II fase do projeto de avaliação da educação médica no Brasil. Rio de Janeiro: Cinaem; 1997.

17. Batista NA, Souza da Silva SH. O professor de medicina: conhecimento, experiência e formação. São Paulo: Edições Loyola; 1998.

18. Cunha MI. O futuro já é hoje: o desafio político-epistemológico do ensino superior na sociedade contemporânea. Anais do $7^{\circ}$ Encontro Nacional de Didática e Prática de Ensino; 1994; Goiânia. p.382-94.

19. Bireau A. Os métodos pedagógicos no ensino superior. Porto: Porto Ed; 1995.

20. Abreu MC, Masetto MT. O professor universitário em aula. São Paulo: MG Editores Associados; 1997.

21. Zabalza MA. O ensino universitário: seu cenário e protagonistas. São Paulo: Artmed; 2004.

22. Venturelli J. Educación médica: nuevos enfoques, metas y métodos. Washington (DC): OPS; 1997.

23. Batista N, Batista SH. A docência em saúde: desafios e perspectivas. In: Batista N, Batista SH, organizadores. Docência em saúde: temas e experiências. São Paulo: Senac; 2004. p.17-31.

24. Perez Gómez AP. O pensamento prático do professor: a formação do professor como profissional reflexivo. In: Nóvoa A, organizador. Os professores e sua formação. Lisboa: Publicações Dom Quixote; 1997. p.95-114. 
25. Brasil. Lei n 9394 de 20/11/1996. Diretrizes e Bases da Educação Nacional. Brasília: 1996.

26. Costa NMSC. A formação e as práticas educativas de professores de medicina [tese]. São Paulo: Pontifícia Universidade Católica de São Paulo; 2005.

27. Mizukami MGN. Teoria, prática e reflexão na formação do profissional em educação. Inter-ação. 1997; 21(1-2):39-60.

28. Perrenoud P. Práticas pedagógicas: profissão docente e formação: perspectivas sociológicas. Lisboa: Publicações Dom Quixote; 1993.

29. Carvalho AMP. Paradigmas e métodos de investigação nas práticas de ensino: aspectos epistemológicos. Anais do $7^{\circ}$ Encontro Nacional de Didática e Prática de Ensino. Goiânia; 1994. p.79-90.

30. Benedito AV. La formación universitaria a debate. Barcelona: Universidad de Barcelona; 1995.

31. Sacristán G. O Currículo: uma reflexão sobre a prática. Porto Alegre: Artmed; 2000.

32. Masetto MT, organizador. Docência na universidade. Campinas: Papirus; 1998.

33. Masetto MT. O professor universitário e sua formação pedagógica. In: Bicudo MAV, Silva Junior CA. Formação do educador e avaliação educacional: formação inicial e contínua. São Paulo: Unesp; 1999.

34. Masetto MT. Competência pedagógica do professor universitário. São Paulo: Summus; 2003.

35. Garcia CM. Formação de professores: para uma mudança educativa. Porto: Porto Editora; 1995.

36. Schmidt LM, Ribas MH, Carvalho MA. A prática pedagógica como fonte de conhecimento. In:
Alonso M, organizador. O trabalho docente: teoria e prática. São Paulo: Pioneira; 1999. p.20-36.

37. Castanho MELM. A criatividade na sala de aula universitária. In: Veiga IPA, Castanho MELM. Pedagogia universitária: a aula em foco. Campinas: Papirus; 2000. p.75-89.

38. Garcia CM. A formação de professores: novas perspectivas baseadas na investigação sobre o pensamento do professor. In: Nóvoa A, organizador. Os professores e sua formação. Lisboa: Publicações Dom Quixote; 1997. p.51-73.

39. Schon D. Formar professores como profissionais reflexivos. In: Nóvoa A, organizador. Os professores e sua formação. Lisboa: Publicações Dom Quixote; 1997. p.77-91.

40. Schon D. Educando o profissional reflexivo. Porto Alegre: Artmed; 2000.

41. Nóvoa A. Formação de professores e profissão docente. In: Nóvoa A, organizador. Os professores e sua formação. Lisboa: Publicações Dom Quixote; 1997. p.15-33.

42. Alonso M. Formar professores para uma nova escola. In: Alonso M, organizador. O trabalho docente: teoria e prática. São Paulo: Pioneira; 1999. p.9-18.

43. Santos LLCP. Formação de professores e qualidade de ensino. In: Escola básica. Campinas: Papirus; 1992. p.137-46.

44. Cunha MI. O professor universitário na transição de paradigmas. Araraquara: JM Ed; 1998.

Recebido em: 15/2/2007

Versão final reapresentada em: 22/4/2008 Aprovado em: 16/7/2008 